\title{
Uma avaliação empírica da lei geral da acumulação capitalista no período atual de globalização neoliberal
}

Paul Cooney ${ }^{1}$

Resumo: Este artigo visa primeiramente examinar as principais teses apresentadas no capítulo 23 do livro 1 de $O$ Capital, que trata da Lei Geral da Acumulação Capitalista, seguido pelo subseqüente debate a respeito das relações entre salários, acumulação e desemprego. A segunda parte do artigo revisita a Lei Geral da Acumulação Capitalista à luz do recente período de globalização neoliberal. Isto é seguido por uma análise empírica para América Latina examinando salários, desemprego, exército industrial de reserva, pobreza, acumulação e desigualdade no período do neoliberalismo. Em geral, os resultados empíricos para o período da globalização neoliberal na América Latina mostram um aumento da pobreza e desemprego e também uma crescente polarização durante o período 1980-2002, seguido por uma ligeira melhora no período 2002-2005. Os resultados apresentados confirmam a validez da lei geral da acumulação capitalista durante o período neoliberal.

Palavras-chave: pobreza; desigualdade; exército industrial de reserva; neoliberalismo.

\section{An Empirical Evaluation of the General Law of Capitalist Accumulation for the Current Period of Neoliberal Globalization}

\footnotetext{
1 Programa de Pós-Graduação em Economia (PPGE), Universidade Federal do Pará (UFPA), Belém, Pará - Brasil. E-mail: pcooney@ufpa.br ou pcooney@glovesoff.org. O autor agradece ao bolsista Wesley Pereira Oliveira que ajudou na tradução do artigo, bem como a Marcelo Dias Carcanholo e Dayani Cris de Aquino pelos comentários e sugestões sobre o texto.
} 
COONEY, P. Uma avaliação empírica da lei geral da acumulação capitalista...

\begin{abstract}
This paper first considers the main points developed by Marx in the chapter on the general law of capitalist accumulation in volume 1 of Capital, followed by a discussion of subsequent debates regarding the relationships between wages, accumulation and unemployment. The second part of this article revisits the general law of capitalist accumulation for the current period of neoliberal globalization. This is followed by an empirical analysis for Latin America, examining wages, unemployment, the industrial reserve army, poverty, accumulation and inequality for the period of neoliberalism. Overall, the empirical results for the period of neoliberal globalization in Latin America show an increase in poverty and unemployment and a growing polarization of wealth for the period 1980-2002, followed by a slight improvement from 2002-2005, and thus provide support for the validity of Marx's general law of capitalist accumulation during the neoliberal period.
\end{abstract}

Keywords: Poverty; Inequality; Industrial Reserve Army; Neoliberalism.

JEL: O54, B51

\title{
Introdução
}

O principal objetivo de Marx em $O$ Capital foi entender as leis que regem o sistema capitalista. Houve uma quantidade significante de pesquisas empíricas examinando preços de produção e a lei do valor, a tendência da equalização das taxas de lucro e a lei da queda tendencial na taxa de lucro, mas bem menos examinada é a lei geral da acumulação capitalista, talvez por ela estar em um nível de análise mais abstrato. Outro motivo é o fato de que os críticos de Marx mostraram a lei geral da acumulação capitalista como uma tese de empobrecimento absoluto, e argumentaram que a lei foi claramente refutada dado o melhoramento do padrão de vida da classe trabalhadora do Primeiro Mundo durante o século passado.

Este artigo visa primeiramente examinar as principais teses apresentadas no capítulo 23 do livro 1 de O Capital, que trata da a Lei Geral da Acumulação Capitalista, e debate a respeito do comportamento dos salários, da acumulação e do desemprego. A segunda parte do artigo revisita a discussão da lei geral da acumulação capitalista à luz do recente período de globalização neoliberal. Isto é seguido por um exame das tendências empíricas para salários, exército industrial de reserva, e a questão da crescente polarização para o atual período de globalização neoliberal. 


\section{Análise de Marx da Lei Geral da Acumulação Capitalista}

Esta seção inicia apresentando o desenvolvimento do argumento de Marx sobre a lei geral da acumulação capitalista no capítulo 23, do livro 1. Marx descreve da seguinte maneira o objetivo desse capítulo:

Neste capítulo, examinaremos a influência que o aumento do capital tem sobre a sorte da classe trabalhadora. Os fatos mais importantes para este estudo são a composição orgânica do capital e as modificações que ele experimenta no curso do processo de acumulação. (Marx 2006:715)

Na primeira seção deste capítulo, Marx considera o caso especial de uma composição orgânica do capital constante e examina a natureza da relação entre salários e acumulação. Marx considera primeiramente o caso que seria mais favorável aos trabalhadores, desde que na ausência de mudança técnica, no qual levaria a um aumento direto na demanda por trabalho com a acumulação. Com a composição orgânica constante, com o capital acumulando, "as necessidades da acumulação do capital ultrapassarem o crescimento da força de trabalho ou do número de trabalhadores, a procura de trabalhadores ser maior que a oferta, ocasionando assim a elevação dos salários. É o que teria de ocorrer, caso não se alterasse a suposição que fizemos anteriormente." (MARX, 2006: 716). Marx fornece suporte histórico para esse argumento, referindo-se ao aumento dos salários durante todo o século XV, e a primeira metade do século XVIII, mas depois buscou demonstrar as restrições necessárias para os aumentos de salário:

O salário, conforme vimos, pressupõe sempre, por natureza, o fornecimento de determinada quantidade de trabalho não-pago por parte do trabalhador. Pondo-se de lado a elevação de salário associada a menor preço de trabalho etc., um acréscimo salarial significa, na melhor hipótese, apenas a redução quantitativa do trabalho gratuito que o trabalhador tem de realizar. Essa redução nunca pode chegar ao ponto de ameaçar a existência do próprio sistema. Deixando-lhe de lado os violentos conflitos em torno da taxa do salário, uma elevação do preço do trabalho, oriundo da acumulação do capital, leva às seguintes alternativas: ou o preço do trabalho continua a elevar-se, por não perturbar essa alta o progresso da acumulação. ...Ou, o outro lado da alternativa, a acumulação retarda-se em virtude de elevar-se o preço do trabalho, ficando embotado o aguilhão do lucro. A acumulação diminui. Mas o decréscimo faz desaparecer a própria causa que o originou, a desproporção entre capital e força de trabalho. O mecanismo da produção capitalista remove os obstáculos que ele mesmo cria temporariamente. (grifo do autor) (ibid.: 722-723) 
COONEY, P. Uma avaliação empírica da lei geral da acumulação capitalista...

Dessa maneira, Marx demonstra que a natureza da relação entre acumulação e salários é tal que os salários são dependentes da acumulação em geral, mesmo que aumentos significativos nos salários conduzissem a um decréscimo inicial da acumulação; é o último que está dominando o movimento geral. Ele argumenta, em termos matemáticos, que "a magnitude da acumulação é a variável independente, e o montante dos salários, a variável dependente, não sendo verdadeira a afirmação oposta" (ibid.: 723). Ao final da primeira seção do capítulo 23, Marx deixa mais clara a relação entre trabalho pago e não-pago, salários e acumulação, como segue:

(...) a relação entre capital, acumulação e salários é apenas a relação entre o trabalho gratuito que se transforme em capital e o trabalho adicional necessário para pôr em movimento esse capital suplementar. Não é de modo nenhum uma relação entre duas grandezas independentes entre si, de um lado a magnitude do capital, do outro o número de trabalhadores; em última análise, é apenas a relação entre trabalho não-pago e trabalho pago da mesma população trabalhadora. (ibid.: 723-724)

Antes de considerar a mudança técnica e os conseqüentes aumentos na composição orgânica do capital, Marx argumenta que:

\footnotetext{
A elevação do preço do trabalho fica, portanto, confinada em limites que mantêm intactos os fundamentos do sistema capitalista e asseguram sua reprodução em escala crescente. A lei da acumulação capitalista, mistificada em lei natural, na realidade só significa que sua natureza exclui todo decréscimo do grau de exploração do trabalho ou toda elevação do preço do trabalho que possam comprometer seriamente (grifo do autor) a reprodução contínua da relação capitalista e sua reprodução em escala sempre ampliada. (ibid.: 724)
}

Como evidente nessa discussão sobre salários e acumulação, Marx não exclui aumentos nos salários reais como um todo, mas que tais aumentos ocorreriam dentro de limites claros estabelecidos pelas necessidades do capital. Mais ainda, ele não argumenta que a taxa de exploração poderia não diminuir em determinados casos, mas que ela pode não continuar diminuindo se ela comprometer seriamente o processo de acumulação capitalista.

Na segunda seção do capítulo 23, Marx relaxa a suposição de uma composição orgânica constante do capital, e considera o impacto da acumulação sobre salários e a classe trabalhadora em geral. Com os avanços da acumulação capitalista, Marx argumenta que isso resulta em um contínuo aumento da produtividade social do trabalho, o qual é refletido no 
aumento da composição orgânica do capital e ainda em uma maior composição técnica do capital, isto é, a massa dos meios de produção em relação à massa de força de trabalho. Dessa maneira, é uma lei da acumulação capitalista que a parte constante do capital continue a aumentar em relação à parte variável do capital.

Neste contexto, Marx discute como o processo de acumulação leva a uma crescente concentração e centralização do capital, como um resultado da concorrência entre capitais individuais. Este último é dependente da necessidade de aumentar a produtividade do trabalho e a expansão da escala de produção. Os processos de concentração e centralização implicam uma tendência para uma quantidade ainda maior de capital necessário para um dado capital permanecer competitivo e, portanto, mais acumulação implica em declínio na proporção de trabalhadores empregados por uma dada magnitude do capital.

Na terceira seção do capítulo 23, Marx apresenta o argumento que segundo o qual como resultado da acumulação, com uma crescente composição orgânica, o capitalismo gera uma superpopulação relativa ou um exército industrial de reserva. Como estabelecido na seção anterior, o progresso da acumulação induz a uma proporção crescente do capital constante em relação ao capital variável; em seguida Marx argumenta:

Sendo a procura de trabalho determinada não pela magnitude do capital global, mas pela magnitude de sua parte variável, ele cai progressivamente com o aumento do capital global, em vez de crescer proporcionalmente com ele, conforme supusemos anteriormente. Diminui em relação à grandeza do capital global e em progressão acelerada quando essa grandeza aumenta. Com o aumento do capital global, cresce também sua parte variável, ou a força de trabalho que nele se incorpora, mas em proporção cada vez menos. (ibid.: 732)

Marx segue mostrando como uma parcela da população torna-se supérflua para as exigências da valorização do capital em decorrência do declínio relativo da parcela variável do capital:

Mas a verdade é que a acumulação capitalista sempre produz, e na proporção da sua energia e de sua extensão, uma população trabalhadora supérflua relativamente, isto é, que ultrapassa as necessidades médias da expansão do capital, tornando-se, desse modo, excedente. (ibid.: 733) 
COONEY, P. Uma avaliação empírica da lei geral da acumulação capitalista...

\subsection{Exército Industrial de Reserva}

Em vários momentos neste capítulo, Marx faz questão de criticar a perspectiva de que as leis da população são universais, isto é, independente dos modos históricos de produção. Como muitos economistas mainstream tentam por a culpa do desemprego nos próprios trabalhadores, Marx demonstra que a formação de um exército industrial de reserva é inerente ao capitalismo, e, como resultado da lei geral da acumulação capitalista, merece mais atenção do que é dada pelos economistas.

\footnotetext{
Por isso, a população trabalhadora, ao produzir a acumulação do capital, produz, em proporções crescentes, os meios que fazem dela, relativamente, uma população supérflua. Está é uma lei da população peculiar ao modo capitalista de produção. Na realidade, todo modo histórico de produção tem suas leis próprias de população, válidas dentro de limites históricos. (ibid.: 734-735)
}

Marx segue argumentando que independentemente do aumento real da população, o capitalismo produz 'uma massa de material humano sempre disponível para exploração do capital', de acordo com as necessidades da valorização do capital. Os períodos alternados de expansão e contração do capitalismo conduzem para uma maior ou menor absorção do exército industrial de reserva, e é durante as fases de crises ou estagnação que a massa do exército industrial de reserva se expande, independentemente da tendência populacional, tampouco como resultado de desemprego 'voluntário'. Marx descreve como a acumulação acelerada leva a uma maior expansão do exército industrial de reserva, e como as estratégias de hora-extra forçada e o processo de desqualificação contribuem para isso.

A condenação de uma parte da classe trabalhadora à ociosidade forçada,
em virtude do trabalho excessivo da outra parte, torna-se fonte de
enriquecimento individual dos capitalistas e acelera ao mesmo tempo
a produção do exército industrial de reserva, nunca escala
correspondente ao progresso da acumulação social. (ibid.: 740)

Tendo estabelecido a formação do exército industrial de reserva no contexto da mudança tecnológica, Marx volta à discussão sobre os salários.

Em seu conjunto, os movimentos gerais dos salários se regulam exclusivamente pela expansão e contração do exército industrial de reserva, correspondentes às mudanças periódicas do ciclo industrial. Não são, portanto, determinados pelas variações do número absoluto da população trabalhadora, mas pela proporção variável em que a 
classe trabalhadora se divide em exército da ativa e exército da reserva, pelo acréscimo e decréscimo da magnitude relativa da superpopulação, pela extensão em que ora é absorvida, ora é liberada. (ibid.: 740-741)

Ele estende essa discussão até a questão de oferta e demanda no mercado de trabalho, fornecendo assim um evidente contraste com a teoria neoclássica dos salários.

Durante os períodos de estagnação e de prosperidade média, o exército industrial de reserva pressiona sobre o exército dos trabalhadores em ação, e, durante os períodos de superprodução e paroxismo, modera as exigências dos trabalhadores. A superpopulação relativa está sempre presente nos movimentos da oferta e da demanda de trabalho. Ela mantém o funcionamento desta lei dentro dos limites condizentes com os propósitos da exploração e de domínio do capital. (ibid.: 742-743)

Na quarta seção do capítulo 23, Marx identifica as três principais formas tomadas pela superpopulação relativa sob o capitalismo: flutuante, latente e estagnada. Marx também faz referência ao "mais baixo sedimento da superpopulação relativa" que reside na esfera do pauperismo, contudo, não fica claro se Marx considera isso uma quarta forma ou simplesmente uma subcategoria da terceira forma, isto é, a estagnação populacional. Marx descreve uma situação depravada para a mais baixa camada da hierarquia social sob o capitalismo, e como tal pauperismo é, no entanto, uma necessidade da produção e riqueza capitalista.

\subsection{A Lei Geral da Acumulação Capitalista}

Marx não só estabeleceu que o funcionamento normal do sistema capitalista leva à existência de uma superpopulação relativa, mas também demonstrou como a acumulação produz uma crescente polarização, com uma riqueza ainda maior de um lado e uma crescente pobreza de outro. Marx identifica isto com a lei geral da acumulação capitalista absoluta.

\footnotetext{
Quanto maiores a riqueza, o capital em função, a dimensão e energia de seu crescimento e, conseqüentemente, a magnitude absoluta do proletariado e da força produtiva de seu trabalho, tanto maior o exército industrial de reserva. ... E, ainda, quanto maiores essa camada de lázaros da classe trabalhadora e o exército industrial de reserva, tanto maior, usando-se da terminologia oficial, o pauperismo. Esta é a lei geral, absoluta, da acumulação capitalista. (ibid.: 748)
} 
COONEY, P. Uma avaliação empírica da lei geral da acumulação capitalista...

Embora Marx descreva essa lei como uma lei geral absoluta, ele imediatamente ressalta que, 'como todas as outras leis, ela é modificada em seu funcionamento por muitas circunstâncias'. ${ }^{2}$ Isto é bastante significante e, como veremos abaixo, muito relevante para aqueles que alegaram que Marx previu um agravamento nunca visto do padrão de vida da classe trabalhadora. De um lado, o número total de pessoas pobres no mundo tem claramente aumentado ao longo do tempo, mas por outro lado, Marx não excluiu a possibilidade de ganhos pela classe trabalhadora através das lutas de classe. Marx enfatizou o crescimento desproporcional entre o trabalho pago e o não-pago, quer dizer, a parcela relativa que vai para a classe trabalhadora poderia continuar diminuindo com o avanço do capitalismo. Neste sentido, poderia haver períodos de aumento do salário real, como ocorreu em muitos países, mas com uma parcela relativa dos salários declinante, comparada a riqueza acumulada em geral.

Na seção final do capítulo 23, Marx fornece exemplos históricos da lei geral da acumulação capitalista. Primeiro, considera o caso da Inglaterra para o período de 1846 a 1866, e também fornece outros exemplos dos relatórios sobre saúde pública inglesa das então décadas recentes durante a metade do século XIX, e também o caso da Irlanda para o este período.

Alguns autores como Strachey (1956) e Sternberg (1955), argumentaram que Marx traçou falsas conclusões gerais devido ao período histórico em que ele estava escrevendo, e, por conseguinte, assumiu erroneamente que o capitalismo levaria a um agravamento nunca visto do padrão de vida da classe trabalhadora. É freqüente o caso, mesmo entre o mais previdentes dos intelectuais, ser influenciado pelo período em que vive; porém, houve interpretações erradas em relação ao que Marx estava argumentando ou antecipando. A seguir, uma discussão de algumas dessas críticas, em particular a 'tese do empobrecimento' e a tese do salário de 'subsistência', será realizada antes de se discutir a lei geral da acumulação capitalista para o período recente de globalização neoliberal.

2 Vale a pena mencionar que as leis gerais do capitalismo, descobertas por Marx, tem um caráter de lei de tendência e não deveriam ser confundidas com qualquer noção de lei no sentido empiricistapositivista. 


\section{Críticas da análise de Marx sobre a Lei Geral da Acumulação Capitalista}

\subsection{A 'Tese do Empobrecimento'}

Braverman (1958) refere-se às 'disputas entre os socialistas, que vêm ocorrendo por mais de meio século', sobre a conhecida 'lei da miséria crescente' e a teoria do salário de 'subsistência' de Marx. Autores como John Strachey ${ }^{3}$ argumenta que Marx já tinha apresentado a 'lei da miséria crescente' assim como a teoria do salário de 'subsistência' em seu capítulo sobre 'Lei Geral da Acumulação Capitalista', e argumenta também que as melhorias significativas nos salários dos trabalhadores britânicos e americanos constituem uma refutação da sua lei geral.

Como Braverman ressalta, "Ambos amigos e inimigos têm interpretado geralmente que isso foi uma teoria na qual os salários deveriam tender a cair, e assim disputaram-a (Braverman 1958:1). Embora em 1847 Marx tenha argumentado em Wage Labour and Capital que as taxas de salários tenderiam a declinar, vários anos mais tarde ele criticava Lassalle por aceitar a 'lei de ferro dos salários' que Ricardo adotou de Malthus. Embora Marx tenha frequentemente usado uma simples suposição de um salário de subsistência, na seguinte passagem de O Capital fica evidente que aqueles que argumentam que Marx teve uma teoria geral do salário de "subsistência" fizeram apenas uma leitura superficial de $O$ Capital de Marx:

Demais, extensão das chamadas necessidades imprescindíveis e o modo de satisfazé-las são produtos históricos e dependem, por isso, de diversos fatores, em grande parte do grau de civilização de um país ...Um elemento histórico e moral entra na determinação do valor da força do trabalho, o que a distingue das outras mercadorias.

(Marx 2006:201)

Marx, portanto, entendeu claramente que o valor da força de trabalho, ou salários, sua forma de preço, não foi limitado a um salário de subsistência, mesmo que ainda isso possa freqüentemente ser o caso para determinados lugares e períodos históricos. Ele entendeu e de fato defendeu o estabelecimento dos sindicatos, de modo que os trabalhadores poderiam melhorar seus salários.

Para os que interpretam Marx como predizendo um absoluto empobrecimento da classe trabalhadora, o aumento significativo no padrão de

3 John Strachey foi um oficial do English Labor Party, membro do Partido comunista Britânico durante os anos 1930 (Veja-se Strachey, 1956). 
COONEY, P. Uma avaliação empírica da lei geral da acumulação capitalista...

vida nos países capitalistas avançados foi visto como uma clara refutação de sua lei geral da acumulação capitalista. Em defesa de Marx, Braverman forneceu um convincente resumo da abordagem teórica de Marx:

\begin{abstract}
No nível puramente teórico, a análise de Marx foi construída de razões, comparações e proporções não absolutas. O desenvolvimento massivo na teoria geral da acumulação capitalista é baseado inteiramente sobre a relação entre trabalho pago e não-pago. É desta que Marx desenvolve suas conclusões econômicas e, mais importante de tudo, é de tal relação que ele deriva a estrutura de classe da sua época - a "polarização da riqueza e da pobreza' no centro de seu pensamento. ${ }^{4}$

(Braverman 1958:2)
\end{abstract}

Todavia, Braverman argumenta que a análise de Marx 'sofre o mal da obsolescência, que ataca até mesmo a melhor das teorias quando elas não recebem as correções requeridas pela passagem do tempo e dos acontecimentos, e assim conclui que a análise de Marx no capítulo 23 não é de 'um erro original, mas obsolescência não corrigida' (ibid.: 2).

Braverman está de acordo com a análise de Marx sobre a relação entre trabalho pago e não-pago, e que o trabalho não-pago é ampliado por três principais motivos identificados por Marx, a saber, um aumento na jornada de trabalho, aumento da intensidade do trabalho e aumentos da produtividade. Ele conclui que como um resultado dos sindicatos, entre outros fatores, o aumento no trabalho não-pago tem sido obtido primeiramente através do aumento da produtividade, e não pelo outros dois motivos. Braverman tem credibilidade por apresentar uma crítica àqueles que atribuem as teorias de salário de subsistência e a 'lei do empobrecimento' à análise de Marx da lei geral da acumulação capitalista. Contudo, como o período histórico atual é tratado na próxima seção, as conclusões de Braverman, baseadas no período em que foram escritas, também requer 'correções requeridas pela passagem do tempo e dos acontecimentos'.

\title{
3. Revisitando a Lei para o Atual Período de Globalização Neoliberal
}

Exatamente como muitos tinham argumentado pela necessidade de revisitar a discussão e conclusões derivadas da lei geral da acumulação capitalista de Marx, dadas as mudanças significativas no padrão de vida da classe trabalhadora da Europa, Estados Unidos e outros países de Primeiro Mundo durante o século XX, as mudanças que a globalização 
neoliberal tem trazido no último quarto de século requer que tudo seja reavaliado novamente. A este respeito, esta seção irá tentar identificar as mais evidentes diferenças para o período atual.

A principal questão metodológica é a unidade de análise que Marx empregou em sua derivação da lei geral da acumulação capitalista. No começo do capítulo 23, Marx limita sua análise para um país.

Por fim, a média geral das composições médias de todos os ramos de produção nos dá a composição do capital social de um país, e que fundamentalmente nos interessa no estudo que se segue.

(Marx 2006:715)

Baseado na citação acima, o nível de análise no capítulo 23 é aquele de um único país, semelhante à abstração usada para a análise das diferentes composições do capital, realizada no capítulo VIII de O Capital, livro 3 (Marx 1987). Contudo, quando considerando o estabelecimento da taxa de lucro geral, no momento atual, é necessário considerar toda a economia global, não apenas um país.

Considerando a lei geral da acumulação capitalista em um contexto global, já não é válido considerar somente um único país, tampouco esperar que a lei seja manifestada para cada país individualmente. Em vez disso, a economia mundial deveria ser tratada como um todo, no sentido de avaliar a validade da lei, especialmente dada a natureza global da economia capitalista atualmente. Isto é particularmente relevante, se forem consideradas as crises, a tendência geral para a polarização ou outros fenômenos gerais com respeito ao capitalismo global, especialmente dada a habilidade do Primeiro Mundo em deslocar os piores excessos do capitalismo, sejam crises, desemprego ou pobreza para o Terceiro Mundo. Portanto, os fenômenos do imperialismo e a atual globalização neoliberal requerem uma unidade de análise diferente da usada por Marx em sua época.

Como visto acima, a discussão sobre melhorias nos salários e os avanços do trabalho através da luta de classe refletem um período histórico particular. Como as previsões, baseadas no tempo em que Marx estava escrevendo poderiam estar incorretas, as previsões de meados do século XX ou dos anos de 1970 poderiam também levar a falsas predições sobre a trajetória do padrão de vida e salários no século XXI. Primeiramente, o novo período de globalização neoliberal tem visto uma mudança de papéis, como o ator dominante da luta de classe sendo empreendida nesse período tem sido a classe capitalista, e não a classe trabalhadora. Segundo, sem levar em conta qual período de tempo está sendo considerado, a tendência de melhorias no padrão de vida tem sido bastante diferente para os trabalhadores do Terceiro Mundo quando 
COONEY, P. Uma avaliação empírica da lei geral da acumulação capitalista...

comparado aos trabalhadores do Primeiro Mundo, e mesmo que o último tenha visto bem mais ganhos como resultado de esforços dos trabalhadores desde o final de século XIX até os anos de 1970, muitos deles retrocederam, se é que não foram perdidos em décadas recentes.

Se considerarmos os quatro pilares principais do neoliberalismo como: (1)liberalização comercial, (2)desregulação financeira, (3)privatizações, e (4)flexibilização do trabalho. Apesar dos três primeiros terem claramente causado danos à classe trabalhadora, o último tem um impacto direto maior sobre os trabalhadores. Pode-se dizer que o impulso em direção ao neoliberalismo é essencialmente o retorno ao laissez-faire. A campanha para forçar a flexibilização do trabalho tem levado a um evidente enfraquecimento dos sindicatos como um todo, e com isso, veio o aumento da jornada de trabalho, da hora-extra e da intensidade de trabalho; uma clara erosão dos direitos dos trabalhadores em todo o mundo. Um dos aspectos notáveis no presente período de globalização neoliberal tem sido o papel desempenhado pelas corporações transnacionais (TNCs) e sua crescente habilidade de aumentar a concorrência entre trabalhadores dos diferentes países, produzindo assim uma espiral descendente para salários e outros benefícios dos trabalhadores.

Uma das principais conclusões alcançadas por Marx no capítulo 23 foi que o movimento geral dos salários foi regulado exclusivamente pela expansão e contração do exército industrial de reserva. Como a análise de Marx sobre o exército industrial de reserva estava assumindo uma única economia e, assim, apenas a classe trabalhadora de um país, no presente contexto global, a capacidade do capital internacional acirrar a concorrência dos interesses dos trabalhadores do Primeiro Mundo contra os trabalhadores do Terceiro Mundo tem alcançado níveis sem precedentes. Como as TNCs estão cada vez mais capazes de estender a produção globalmente, freqüentemente produzindo o mesmo produto em vários países ao mesmo tempo, elas podem conseguir vantagens das piores condições dos trabalhadores no Terceiro Mundo, dado o fato que há um exército industrial de reserva bem maior.

No passado, poderia não fazer sentido mudar a produção para áreas de salários mais baixos, dada à carência de trabalhadores qualificados ou níveis menores de produtividade, mas, atualmente, há trabalhadores qualificados disponíveis na maioria dos países e, assim, os exércitos industriais de reserva existentes no Terceiro Mundo não apenas têm um impacto sobre os salários no Terceiro Mundo, mas as TNCs têm agora até uma maior influência em forçar para baixo os salários no Primeiro Mundo, estabelecendo agora um exército industrial de reserva global.

Durante esse período neoliberal, uma maior proporção de investimentos tem se deslocado da indústria às finanças, e, por conseguinte, uma 
crescente parcela de trabalho improdutivo que tem uma concomitante redução na produção de mais-valia comparado com o período anterior. Este é o principal fator na explicação do fenômeno claramente estabelecido de taxas de crescimento menores durante o período neoliberal. Taxas mais baixas de crescimento têm significado uma menor proporção da população economicamente ativa participando da força de trabalho empregada. Isto implica em um crescimento cada vez maior do exército industrial de reserva sob a globalização neoliberal. Menores oportunidades de emprego regular têm levado a um aumento da economia informal, empregos mais precários, menores salários, e aumentado a pobreza em nível global. Uma análise dessas tendências empíricas sob o período de globalização neoliberal será realizada na próxima seção.

\section{Avaliação empírica da Lei Geral durante o período de globalização neoliberal}

Nesta seção, várias tendências empíricas relacionadas com a lei geral da acumulação capitalista de Marx serão estudadas para o período neoliberal. Como comentado anteriormente, é necessário considerar o exército industrial de reserva global para o atual período de globalização neoliberal, e também medidas preferencialmente globais para outras variáveis. No entanto, isto não é freqüentemente viável, e, portanto, variáveis proxy ou um subconjunto de países são com freqüência utilizados na análise a seguir.

Uma das principais conclusões de Marx sobre a Lei Geral foi que os salários são dependentes da acumulação, e, como conseqüência, das relativas proporções entre o exército industrial da ativa e de reserva. Assim, preferencialmente, uma avaliação empírica da lei geral poderia examinar as séries temporais dos salários, taxas de acumulação, e medidas para o exército industrial da ativa e de reserva. Com respeito à estimação do exército industrial de reserva global, a tarefa é bastante complicada e necessita de tempo, devido a várias razões. A primeira questão é que o conceito teórico de exército industrial de reserva em Marx é bem mais amplo do que simplesmente uma contagem de desempregados e subempregados e também seria desejado estimar o exército industrial da ativa e de reserva. Segundo, há o sério problema de diferentes e enviesadas metodologias usadas pelos órgãos estatísticos nacionais, em termos de compatibilidade entre as numerosas fontes, mas especialmente os intentos em estreitar a definição de população economicamente ativa. ${ }^{5}$

5 Espera-se que colaborações futuras sejam realizadas, no intuito de dar resposta aos problemas citados, e assim, obter uma melhor avaliação empírica da lei geral da acumulação capitalista. 
COONEY, P. Uma avaliação empírica da lei geral da acumulação capitalista...

Outra importante conclusão de Marx no capítulo 23 foi a crescente polarização como resultado da acumulação capitalista - a crescente acumulação da riqueza de um lado, e uma crescente acumulação da pobreza de outro. Mais uma vez, há um grande número de questões teóricas e empíricas. A melhor escolha de uma variável para representar uma medida de riqueza acumulada é discutível e mais uma vez objeto de problema de múltiplas fontes nacionais com distintas metodologias. Para o presente artigo, principalmente pelo fato da disponibilidade dos dados, a formação bruta de capital fixo é a principal variável utilizada.

Em relação à pobreza, medidas globais estão disponíveis no Banco Mundial, contudo, a metodologia usada pelo Banco é claramente defeituosa e tem sido fortemente criticada por alguns autores (ver Pogge \& Reddy 2003).

Apesar da preferência em realizar a análise empírica a um nível global, dadas às dificuldades em obter séries de dados abrangentes e consistentes, assim como restrição de tempo, dados da Comissão Econômica para a América Latina e o Caribe (CEPAL) são usados em geral para a análise a seguir. Embora analisar apenas a América Latina tenha suas claras limitações, isso representa um caso intermediário do Terceiro Mundo no momento, entre África e Ásia em termos de níveis gerais de desenvolvimento econômico. Uma outra vantagem da CEPAL é a não tendência a ter inclinação ideológica tão enviesada como o Banco Mundial, embora ainda haja um viés de classe, por exemplo, a respeito da disponibilidade de dados sobre salários.

\subsection{Período de análise}

A medida da possibilidade, dados de 1980 até 2005 são usados na análise empírica, embora se possa discutir sobre outros anos para identificar o início da globalização neoliberal. Em certo sentido, a escolha de 1980 é arbitrária, mas na verdade, as séries de dados disponíveis geralmente ditam a escolha dos anos analisados.

\subsection{Salários}

Embora a OIT possua taxas de salários reais disponíveis, elas estão expressas em moedas locais para cara ano dado, e ainda necessita-se de uma substancial quantidade de manipulação nesses dados para que eles se tornem consistentes. ${ }^{6}$

6 Embora esta análise esteja atualmente sendo realizada, ainda não está disponível. 
Dado que seus dados sobre taxas de salários para a América Latina são razoavelmente consistentes, o banco de dados da CEPAL foi utilizado. A série disponível mais abrangente foi o salário mínimo real urbano, abrangendo 17 países latino-americanos, para o período de 1980-1998, usando 1995 como benchmark igual a 100. Houve um declínio acentuado das taxas médias de salário mínimo entre 1980 e 1990, caindo de aproximadamente 204 para 103. Isso foi seguido por uma ligeira melhora entre 1990 e 1998, subindo de 103 para 107,6. Apesar das distorções em usar um índice baseado num benchmark, a tendência geral e a média para a América Latina (a linha preta mais grossa) das taxas de salário durante o período neoliberal são evidentes na Figura 1 abaixo. ${ }^{7} \mathrm{~A}$ média simples da mudança percentual declina entre 1980 e 1990 em $31,4 \%$; entre 1990 e 1998 aumenta em $24 \%$, e para todo o período de $1980-$ 1998, há um declínio de $26 \%$. Incluindo pesos para a população economicamente ativa, a mudança percentual declina entre 1980 e 1990 em $39,2 \%$; entre 1990 e 1998 aumenta em $28,5 \%$, e para todo o período de 1980-1998, há um declínio de $28 \% .^{8}$

FIGURA 1- SALÁRIO MÍNIMO REAL URBANO NA AMÉRICA LATINA $(1995=100)$

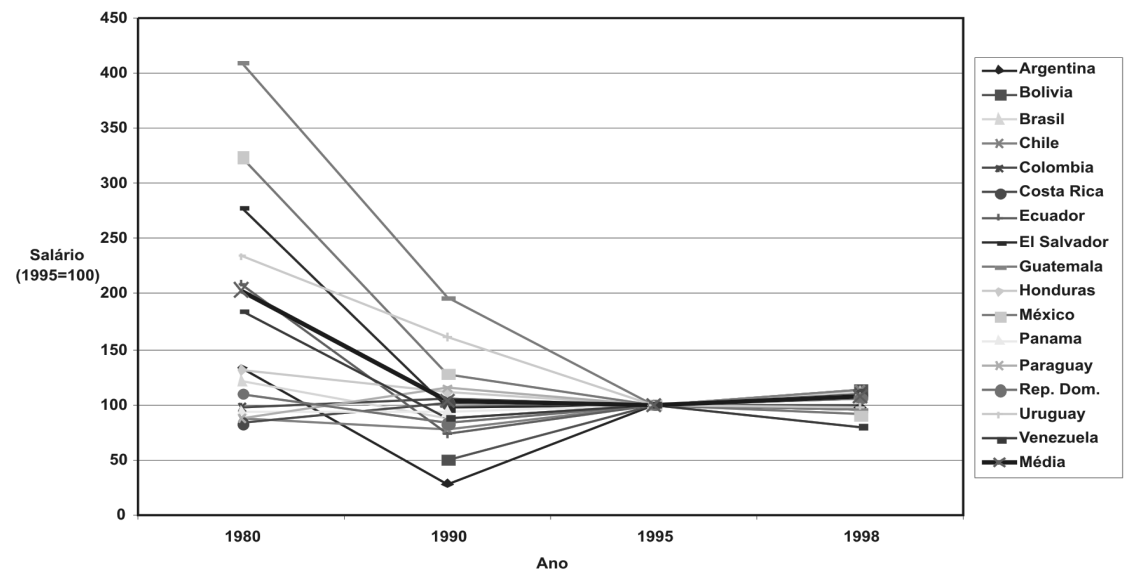

Fonte: CEPAL, 2007.

Embora a cobertura tivesse menos abrangência em termos tanto de países (13) quanto de anos, a taxa de salário média real foi examinada para os anos 1980, 1990, 1995 e 1998, como vemos na Figura 2 abaixo. Há claramente menor declínio da taxa de salário média total entre 1980 e

7 Embora incluído na análise numérica, o Peru foi excluído das Figuras devido a sua taxa de salário ser tão elevada para o ano de 1980 que a Figura resultante impediu de diferenciar as tendências salariais individuais dos países.

8 Devido à limitação de dados disponíveis, apenas 13 dos 17 países foram usados para calcular as médias ponderadas. 
COONEY, P. Uma avaliação empírica da lei geral da acumulação capitalista...

1990, caindo de aproximadamente 124 para 92; seguido por uma melhora entre 1990 e 1998, elevando de 92 para 103. A média simples da mudança percentual declina entre 1980 e 1990 em 12,26\%; entre 1990 e 1998 aumenta em 15,07\%, e para todo o período de 1980-1998, aumenta em 2,66\%. Contudo, para o mesmo período, a média simples de salário para a América Latina caiu de 123,88 para 102,65; um declínio de $17,13 \%$. Incluindo pesos para a população economicamente ativa, a mudança percentual entre 1980 e 1990 é 6,76\%; entre 1990 e 1998 há um aumento de 7,03\%, e para todo o período de 1980-1998, há um aumento de $0,22 \%$.

Dois dos países mais industrializados da América Latina, Argentina e México, têm mostrado um forte declínio nos salários durante o período neoliberal. No caso da Argentina, a partir de meados da década de 1990, os salários reais não retornaram nem mesmo a $60 \%$ do nível que tiveram em meados da década de 1970, quando eles iniciaram uma mudança em direção às políticas neoliberais. Para o caso do México, os salários reais manufatureiros são ainda aproximadamente $70 \%$ do nível alcançado em 1980. ${ }^{9}$

\section{FIGURA 2- SALÁRIO MÉDIO REAL NA AMÉRICA LATINA (1995=100)}

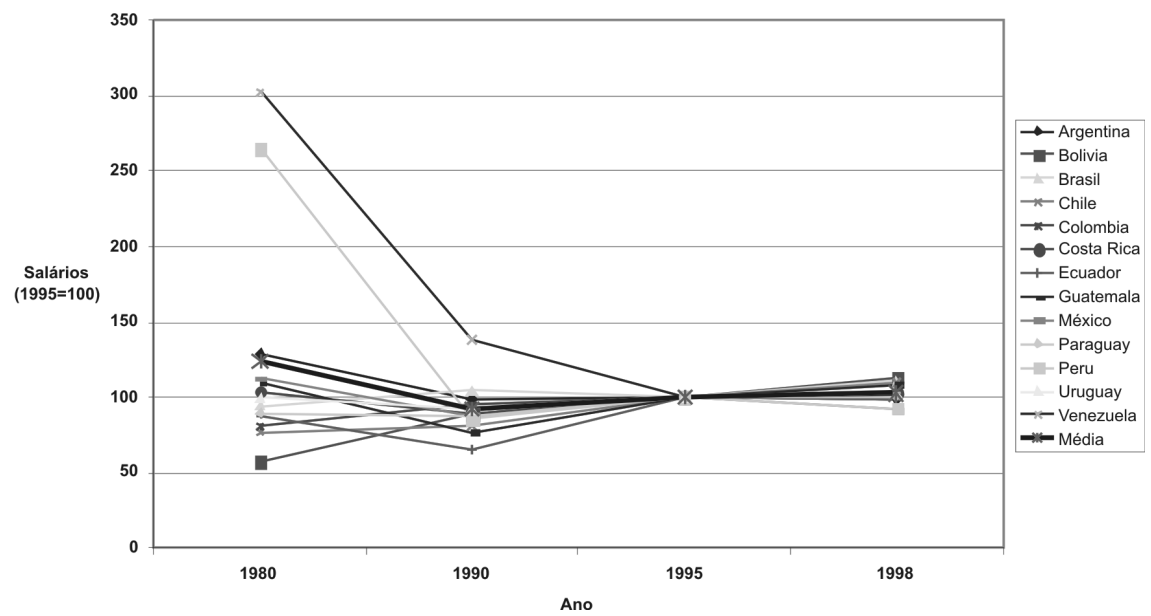

Fonte: CEPAL, 2007.

\subsection{Exército Industrial de Reserva/Desemprego}

Como mencionado anteriormente, uma medida apropriada do exército industrial de reserva precisa incluir não apenas os trabalhadores que

9 Para uma discussão mais aprofundada sobre a Argentina, ver Cooney, 2007a; para México, Cooney (2001, 2007b). 
estão desempregados, mas também os parcialmente empregados. A definição padrão usada para desempregado não inclui aqueles parcialmente empregados, tampouco aqueles que estão procurando emprego. Para alguns países (a exemplo do $\mathrm{México}^{10}$ ), se o trabalhador trabalha apenas uma hora por semana, ele é considerado empregado. Recentemente também vêm ocorrendo mudanças mais restringidas na definição de desemprego, por exemplo, Argentina em 2003 e Brasil em 2002. Portanto, as estimativas obtidas tenderão a subestimar cada vez mais o desemprego para anos recentes. Estas mudanças implicam discrepância ainda maior entre desempregados e o exército industrial de reserva, que é necessário para examinar empiricamente a validade da lei geral da acumulação capitalista. Têm-se realizado algumas pesquisas para países individuais que estimam subempregados e a ampla categoria que inclui aqueles que têm procurado emprego (exemplo de Mariña Flores, 2004). Assim, a fim de medir apropriadamente o exército industrial de reserva global, tal pesquisa detalhada é requerida para todos os países, seguido por uma sistematização para finalidade de consistência. Infelizmente, isto não é possível no momento, mas talvez através de um esforço conjunto isso seja viável em um futuro próximo. Portanto, a análise a seguir é limitada por ter que usar medidas de desemprego como uma proxy para o exército industrial de reserva.

Frente às dificuldades com os dados disponíveis da OIT, o banco de dados da CEPAL foi mais uma vez selecionado para examinar a taxa de desemprego para o período neoliberal. Devido à cobertura limitada, a taxa de desemprego urbano foi usada para os seguintes anos: 1980, 1985, 1990, 1995, 2000, 2003 e 2004. As taxas de desemprego urbano para 18 países da América Latina e a média global são mostradas na Figura 3 abaixo. A tendência para a média é claramente ascendente, crescendo de 6,2\% em 1980 para 10,7\% em 2003, e depois caindo ligeiramente para $10 \%$ em 2004.

No relatório da CEPAL (2005-2006) havia dados para a média global ponderada de taxas de desemprego para 23 países da América Latina, mas iniciando apenas no ano de 1991. Isso mostrou uma tendência semelhante ao resultado acima para os anos de 1990, como a média ponderada de desemprego passou de 9,9\% em 1991 alcançando $11 \%$ em 2002 e 2003, e depois reduzindo para 10,2\% para 2004.

Usando dados para a população economicamente ativa e taxas de desemprego urbano, foram realizadas estimações do número total de desempregados na América Latina durante o período de 1980 a 2000. Embora as taxas de desemprego global fossem preferidas, elas não esta-

10 As estatísticas oficiais para desemprego no México são extremamente restritivas; medidas alternativas precisam ser empregadas para uma análise mais precisa, como realizada por Marina Flores, 2004 
COONEY, P. Uma avaliação empírica da lei geral da acumulação capitalista...

vam disponíveis para os anos anteriores a 1991. Em todo caso, para os anos onde as séries eram disponíveis, elas foram semelhantes às taxas de desemprego urbano, embora sempre ligeiramente maior. Em 1980, a estimação do número total de desempregados para estes dezoito países latino-americanos foi de aproximadamente 7,5 milhões de pessoas (7.460.647), e este cresceu 185\%, alcançando mais de 21 milhões de pessoas (21.264.658) em 2000. Durante esse mesmo período de tempo, a população desses 18 países aumentou de aproximadamente $337 \mathrm{mi}$ lhões para mais de 492 milhões, com um aumento de apenas 46\%, nem mesmo um quarto do aumento de desempregados. Isso é uma clara evidência de que o crescimento do desemprego não está acompanhando o ritmo do crescimento populacional, e que o exército industrial de reserva tem claramente aumentado durante o período de globalização neoliberal na América Latina.

\section{FIGURA 3- TAXAS DE DESEMPREGO URBANO NA AMERICA LATINA}

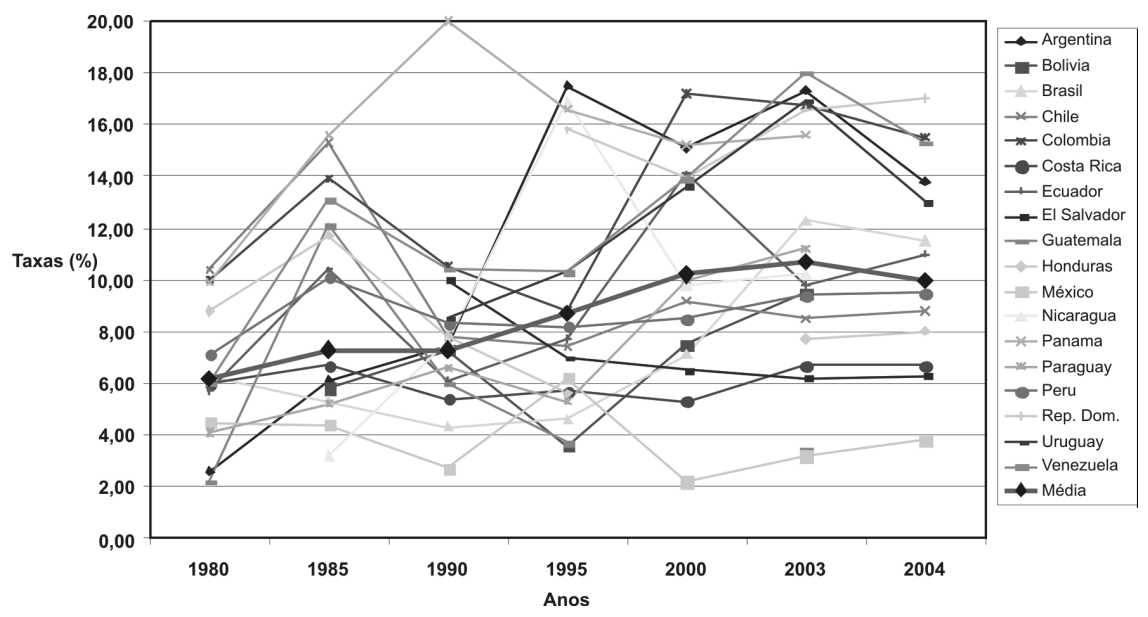

Fonte: CEPAL, 2007.

\subsection{Pobreza}

Como mencionado acima, a metodologia usada pelo Banco Mundial tem recebido forte crítica por subestimar seriamente a pobreza, para justificar as políticas neoliberais pregadas pelo FMI e Banco Mundial. Graças a grandes esforços de autores como Pogge and Reddy, o debate sobre como medimos pobreza tem intensificado. ${ }^{11}$ Há também aqueles ideólogos do capitalismo, em particular Sala-i-Martin e Barros,

11 Para um breve resumo sobre esse debate, ver Burke (2003), no site da Gloves Off. 
argumentando que o Banco Mundial está superestimando a pobreza, e defendendo que a pobreza tem declinado muito mais do que o estimado pelo Banco Mundial. ${ }^{12}$ Algumas questões são de natureza bastante técnicas, assim uma tentativa de mostrar uma crítica mais clara da metodologia seguida pelo Banco Mundial será realizada a seguir.

Há três principais críticas sobre a metodologia do Banco Mundial apresentadas por Pogge and Reddy. O primeiro problema é que o Banco Mundial não define pobreza em termos de acesso de um mínimo de necessidades básicas, como alimentação e moradia, e, portanto, ajusta um nível arbitrariamente baixo para a linha internacional de pobreza (LIP ou IPL), tratando pessoas como pobre se, e somente se, seu rendimento diário tem menos poder de compra que \$1/dia nos Estados Unidos em 1985. Segundo, o Banco usa as paridades de poder de compra (PPCs) que são baseadas nos preços médios de todas as commodities, não apenas aquelas necessárias para as pessoas pobres. O terceiro principal problema é que devido as estimações do Banco serem baseadas em dados um tanto limitados que variam de país para país em sua consistência, eles expressam um falso senso de precisão. Infelizmente, os dados do Banco Mundial estão sendo usados e citados por muitas organizações internacionais, incluindo as Nações Unidas, e pela maioria dos economistas, inclusive aqueles que se consideram progressistas.

Dado os problemas citados, apesar da cobertura global, os dados do Banco Mundial são inadequados para análise empírica. Portanto, como no caso de outros dados analisados, a análise para a América Latina foi realizada usando o banco de dados da CEPAL, que é significativamente mais confiável que o Banco Mundial.

Baseado nos dados da CEPAL, o nível geral de pobreza para a América Latina foi de 40,5\% em 1980, aumentando para 48,3\% em 1990; mas tem apresentado uma melhora, caindo para $44 \%$ em 2002. Há também uma tendência similar para os níveis gerais de indigência, indo de 18,6\% em 1980 para 22,5\% em 1990, e depois declinando para 19,4\% em 2002.

Com visto na Figura 4 abaixo, o número total de pessoas vivendo na pobreza na América Latina (18 países) aumentou de 136,5 milhões em 1980 para 223,3 milhões em 2002. Houve posteriormente uma redução da pobreza em 2005, caindo para 211,5 milhões. Isto implica que houve um aumento percentual geral de $63,5 \%$ de pessoas vivendo na pobreza na América Latina entre 1980 e 2002, com um declínio de 5,2\% entre 2002 e 2005 .

12 Por exemplo, para o caso de $\$ 1$ dia representando a linha internacional de pobreza, o Banco Mundial estima um total de 1,2 bilhões de pessoas para 1990, enquanto Sala-i-Martin defende que se trata de meros 286 milhões (ver Nye, Pogge \& Reddy 2002). 
COONEY, P. Uma avaliação empírica da lei geral da acumulação capitalista...

FIGURA 4 - POBREZA NA AMÉRICA LATINA: 1980-2005

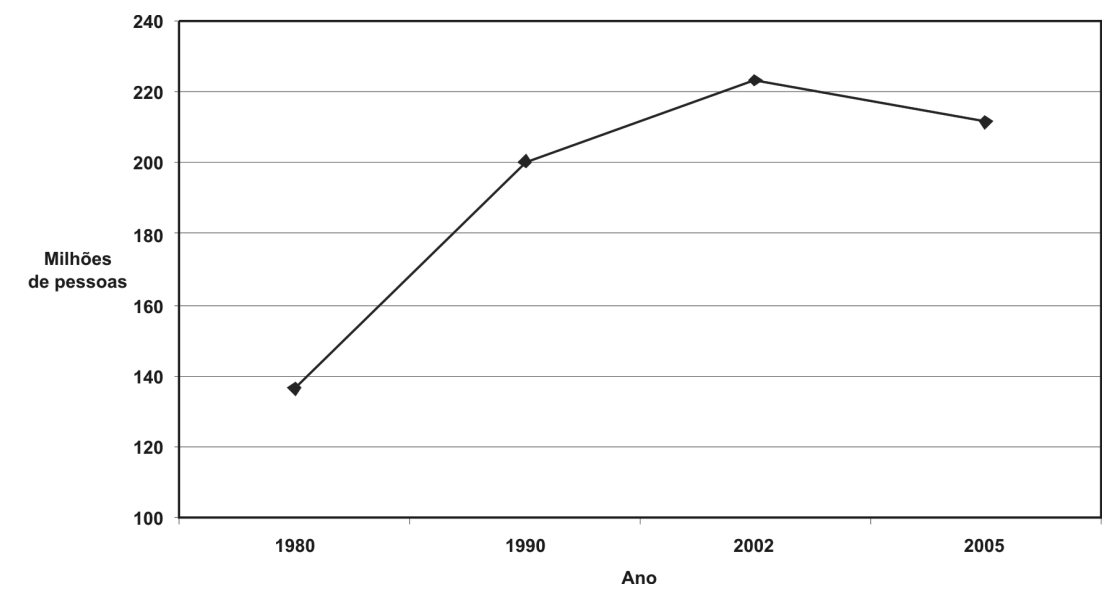

Fonte: CEPAL, 2007.

4.5 Acumulação

Embora a riqueza geral das classes capitalistas fosse preferida, uma medida legítima de acumulação é a série de dados da Formação Bruta de Capital Fixo (FBCF), e como no caso dos dados anteriores, apenas a América Latina será estudada. Entre 1990 e 2005, a formação bruta de capital fixo para a América Latina como um todo (32 países) aumentou de aproximadamente US\$ 244,5 bilhões em 1990 para aproximadamente US \$ 427 bilhões em 2005, um aumento de 74,5\% para um período de 15 anos. Infelizmente, dados da CEPAL para períodos mais recentes, de 1980 a 1990, não estão prontamente disponíveis, mas espera-se obtê-los brevemente.

\subsection{Pólos de riqueza e pobreza}

A fim de examinar empiricamente a principal conclusão da lei geral da acumulação capitalista de Marx, a saber, a tendência inerente para a polarização crescente da riqueza e da pobreza, como a acumulação capitalista prossegue, foi discutido que uma análise global se faz necessária. A Tabela e a Figura a seguir com dados sobre distribuição de renda do PNUD (UNDP) fornecem uma clara indicação da crescente desigualdade que tem ocorrido durante o período de globalização neoliberal para o mundo como um todo. Durante esse período de quase quatro décadas, os mais ricos aumentaram sua parcela de renda de 70\% para quase $90 \%$. Durante este mesmo período de tempo, os 20\% mais pobres experimentaram um declínio de $2,3 \%$ para um mero $1,2 \%$ do total da 
renda. Além do declínio para os 20\% mais pobres há também um declínio bastante significativo para os $60 \%$ médios, caindo de $27,5 \%$ do total da renda para 9,8\% em 1998. Estas estatísticas globais vão contra as alegações do FMI e do Banco Mundial e ainda algumas divisões das Nações Unidas, que afirmam que a globalização tem ajudado a reduzir a desigualdade.

TABELA 1 - DADOS DA PNUD SOBRE DESIGUALDADE GLOBAL: 1960-1998

\begin{tabular}{llllll}
\hline $\begin{array}{l}\text { Distribução da } \\
\text { Renda }\end{array}$ & 1960 & 1970 & 1980 & 1989 & 1998 \\
\hline $\begin{array}{l}\text { 20\% mais } \\
\text { pobre }\end{array}$ & $2,30 \%$ & $2,30 \%$ & $1,70 \%$ & $1,40 \%$ & $1,20 \%$ \\
$\begin{array}{l}60 \% \\
\text { intermediários }\end{array}$ & $27,50 \%$ & $23,60 \%$ & $22,00 \%$ & $15,90 \%$ & $9,80 \%$ \\
$\begin{array}{l}20 \% \text { mais } \\
\text { ricos }\end{array}$ & $70,20 \%$ & $73,90 \%$ & $76,30 \%$ & $82,70 \%$ & $89,00 \%$ \\
\hline
\end{tabular}

FIGURA 5- DADOS DO PNUD SOBRE DESIGUALDADE GLOBAL:1960-1998

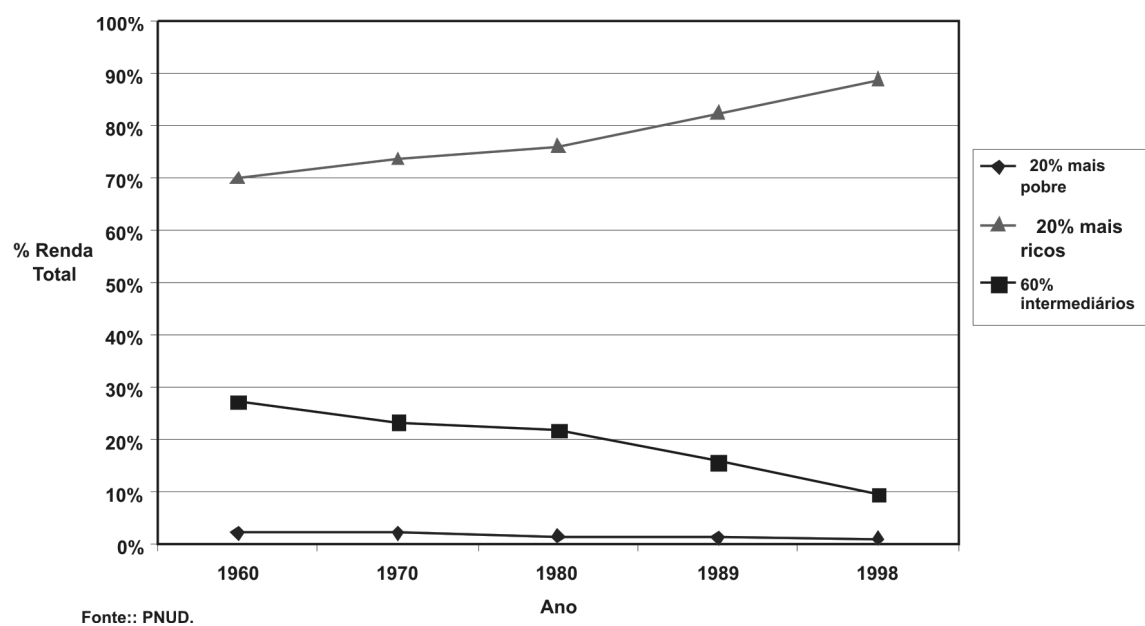

A Figura 6 abaixo fornece uma ilustração revelando a desigualdade da riqueza e a luta de classe no caso dos Estados Unidos. Há um claro declínio no percentual dos bens totais possuídos pelos $1 \%$ mais ricos da população dos EUA para meados de 1920 até meados da década de 1970. 
COONEY, P. Uma avaliação empírica da lei geral da acumulação capitalista...

Isto é seguido por uma evidente recuperação da classe capitalista dos EUA iniciando no fim dos anos 70 ou início dos 80, crescendo de menos de $25 \%$ da riqueza total para mais de $35 \%$ em meados dos anos de 90 . Há também uma clara estabilização em meados da década de 1990, sugerindo que os ganhos da classe capitalista dos EUA foram menos significativos do que durante a primeira década e meia do neoliberalismo. Isto é congruente com a tendência geral observada para a América Latina anteriormente.

Uma avaliação adequada deste Gráfico requer uma análise histórica mais detalhada do que pode ser feita no momento, contudo, algumas observações merecem ser mencionadas. De um lado, a Segunda Grande Depressão dos anos de 1930 claramente teve um impacto negativo sobre os americanos mais ricos, mas também as políticas do New Deal e a atividades sindicais significativos, através da luta de classes levou a uma mudança da riqueza em favor da classe trabalhadora americana. É claro que por volta do final da década de 1970, a classe capitalista americana tomou a iniciativa e os $1 \%$ mais ricos recuperaram mais de $10 \%$ de toda a riqueza em aproximadamente 15 anos. Mais uma vez, tal fenômeno é suporte da tendência no sentido da polarização para o capitalismo laissez-faire, mas no intuito de explicar inteiramente tal fenômeno, tal como o declínio do percentual da riqueza total da classe capitalista dos Estados Unidos, requer uma análise da luta de classes para melhorar tanto a nossa compreensão empírica das leis do capitalismo assim quanto as tendências históricas durante períodos diferentes. Antes de chegar às conclusões, a seguinte citação e comentário fornecem um saliente insight. De acordo com o PNUD: "A desigualdade da renda nacional (medida pela taxa de câmbio de mercado) entre os cinco primeiros países de renda mais alta e os cinco de renda mais baixa tem aumentado para algo em torno de 72 por $1 .{ }^{13}$ Os autores Pogge, Reddy e Nye apontam para o fato de que:

\footnotetext{
Apenas 1\% da renda nacional dos países de renda mais alta seria suficiente para aumentar a renda dos países de renda mais baixa (onde vive a maioria das pessoas mais pobres do mundo) em $72 \%$. Vale a pena apontar isso em um mundo em que pelo menos um terço de todas as mortes estão relacionadas com a pobreza. (Pogge, Reddy \& Nye 2003:1). ${ }^{14}$
} 
FIGURA 6- PARCELA DOS ATIVOS DETIDOS PELO 1\% MAIS RICO DA POPULAÇÃO DOS EUA -: 1922-1988

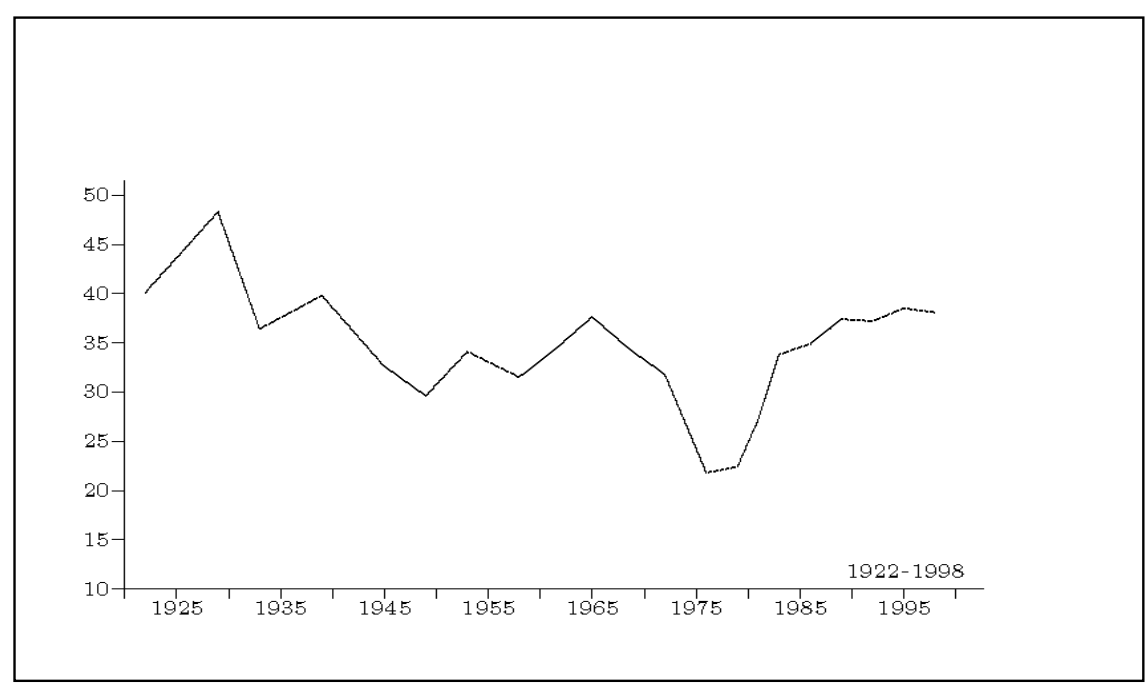

Fonte: Duménil \& Lévy 2004.

5. Conclusões

Este artigo iniciou examinando as principais teses desenvolvidas por Marx em seu capítulo sobre a lei geral da acumulação capitalista. A primeira sendo a relação dependente dos salários na acumulação, ambos no contexto de uma constante, e depois uma composição orgânica crescente do capital. A segunda principal tese discutida foi a de que em conseqüência de um relativo declínio do capital variável, a acumulação conduziu para a formação de um exército industrial de reserva e que os salários dependiam de proporções relativas do exército da ativa e da reserva do trabalho. Posteriormente, a outra importante conclusão foi que como a acumulação capitalista progrediu, haveria crescente riqueza em um pólo, e a crescente pobreza em outro.

Muitos dos críticos da análise de Marx foram posteriormente mostrados tanto por uma interpretação errônea de Marx, que não alegava que haveria uma pobreza absoluta da classe dos trabalhadores, quanto por uma leitura superficial de Marx, alegando que ele tinha uma teoria de salário de subsistência. Muitas das críticas, parecidas derivar da suposição de que o padrão de vida da classe dos trabalhadores era continuar melhorando indefinidamente e de sua alegação sobre o empobrecimento, implicaram que Marx foi indevidamente influenciado pelo período histórico em que ele escreveu. Ainda que Marx argumentou sobre um empobrecimento relativo, que ainda foi válido durante todo o século 
COONEY, P. Uma avaliação empírica da lei geral da acumulação capitalista...

$\mathrm{XX}$, este artigo discutiu que há necessidade de se considerar o mundo como um todo para tratar a tendência de polarização. Portanto, para este atual período de globalização neoliberal, necessita-se considerar o exército industrial de reserva global e reconhecer que os piores excessos do capitalismo ocorrem no Terceiro Mundo.

A segunda parte desse artigo dedicou-se a uma análise empírica da acumulação, dos salários, do exército industrial de reserva, e da desigualdade crescente. Embora a intenção original desse artigo fosse conduzir a uma análise global, devido à disponibilidade de dados e ao tempo restrito, a região da América Latina foi usada em vez disso. Como descrito acima, os principais resultados mostram que durante o período de globalização neoliberal a pobreza na América Latina claramente cresceu, um aumento de $63,5 \%$ entre 1980 e 2002, com um ligeiro declínio de $5,2 \%$ entre 2002 e 2005 .

O desemprego na América Latina, uma proxy para o exército industrial de reserva, apresentou resultado semelhante com um aumento constante de 1980 até 2003, ponto em que começou a declinar, crescendo a uma taxa de $185 \%$, bem acima da taxa de crescimento da população, que foi de $46 \%$. No caso das taxas de salários, houve claramente uma deterioração durante a década de 1980 e uma melhora na de 1990, com um resultado líquido para o período de 1980-1998 permanecendo impreciso, dependendo sobre qual série de dados está sendo considerada. Em todo caso, apresenta na melhor das hipóteses uma ligeira melhora, e na pior um claro declínio geral. Infelizmente, os dados para acumulação apenas cobriram o período de 1990 até 2005 e, devido a isso, mais comparações empíricas, a exemplo de um modelo econométrico, não foram perseguidas.

Os resultados empíricos sugerem que como o neoliberalismo ou o capitalismo laissez-faire, tornou o modelo econômico dominante na América Latina, que levou a uma crescente polarização como o capital transnacional avançou em seu plano global. Parece que como conseqüência de tais piores condições, está também ocorrendo um aumento da insatisfação com o neoliberalismo, como presenciado pela mudança no sentido esquerdista na América Latina. Apesar do fato de que muitos dos novos governos de 'esquerda' não romperam com o neoliberalismo, o papel dos movimentos sociais tem sido capaz de colocar este modelo em xeque, forçando os governos a introduzirem políticas sociais, voltadas para os piores excessos do neoliberalismo, e assim levando a ligeira melhora em anos recentes com relação aos salários, à pobreza e ao desemprego.

Em outras palavras, como o neoliberalismo contribuiu para a eliminação dos ganhos conseguidos arduamente pela classe trabalhadora, as 
tendências inerentes do capitalismo tornaram-se mais evidente, agravando as condições de vida da maioria da população do mundo, a crescente polarização e a pobreza e, assim, causando um aumento na mobilização dos movimentos sociais. Tais respostas, têm levado cada vez mais as principais instituições internacionais, a saber, o FMI e o Banco Mundial, a dar atenção e, em último, caso a ajustar seus discursos, e em alguns casos fazem um esforço para evitar piores excessos da globalização neoliberal.

Em conseqüência dessa tentativa inicial de analisar empiricamente a lei geral da acumulação capitalista no contexto do atual período de globalização neoliberal, tornou-se evidente que há necessidade de uma análise histórica mais aprofundada, melhorando não apenas as séries de dados estudadas, mas também pesquisando os tipos específicos de mudanças políticas e programas sociais que têm desempenhado um papel amenizador em anos recentes.

Em suma, os resultados gerais observados são consistentes com a análise de Marx da lei geral da acumulação capitalista, e também com a sua compreensão de como os piores excessos do capitalismo fornecem impulso para a luta de classe. O agravamento da pobreza e da desigualdade durante o período de globalização neoliberal, como resultado do avanço do capital global, sugere uma necessidade jamais vista por uma contra-ofensiva coordenada pela classe trabalhadora global.

\section{Referências}

BRAVERMAN, Harry (1958). "Marx in the Modern World", American Socialist, May, 1958. URL: http: //www.marxists.org/history/etol/newspape/ amersocialist/amersoc_5805.htm.

BURKE, Sara (2003). "Stats on Poverty? Or the Poverty of Stats?, Gloves Off -Bare-Fisted Political Economy. URL: http: //www.glovesoff.org/ ringside_reports/poverty_040603.html.

COONEY, P. (2007a). “Argentina's Quarter Century Experiment with Neoliberalism: From Dictatorship to Depression." Revista de Economia Contemporânea. Rio de Janeiro, Vol. 11, Nro. 1, jan./abr., 2007.

COONEY, P. (2007b). "Dos Décadas de Neoliberalismo en México- Resultados y Desafíos", aprovado pelo XXXV Encontro Nacional de ANPEC, dezembro, 2007.

COONEY, P. (2001). "The Mexican Crisis and the Maquiladora Boom, A Paradox of Development or the Logic of Neoliberalism." Latin American Perspectives. Riverside, California, Vol. 28, No. 3 May 2001.

DUMÉNIL, G. \& LÉVY, D. (2004). Capital Resurgent. Roots of the Neoliberal Revolution. Harvard: Harvard University Press. 
COONEY, P. Uma avaliação empírica da lei geral da acumulação capitalista...

ECLAC (2004). "Statistical Yearbook for Latin America and the Caribbean". URL: http: //www.eclac.cl.

MARIÑA FLORES, Abelardo (2004). "Las condiciones actuales del empleo urbano en México: agravamiento coyuntural de una situación de precariedad estructural" en El Cotidiano 20(20).

MARX, K. (2006) O Capital: crítica da economia política. $21^{\mathrm{a}}$ ed. Rio de Janeiro: Civilização Brasileira.

MARX, K. (1987). O Capital, Livro 3. DIFEL, Rio de Janeiro.

MARX, K. (1933). Wage Labour and Capital, International Publishers, New York.

MARX, K. (1962). Engels Werke, vol. 23, Dietz Verlag, Berlin.

NYE, H. \& POGGE, T. \& REDDY, S. (2002). "What is Poverty". The New York Review of Books 49(18).

POGGE, T. \& REDDY, S. (2003). "Unknown: The Extent, Distribution, and Trend of Global Income Poverty". URL: www.socialanalysis.org/

POGGE, T. \& REDDY, S. \& NYE, H. (2003). "The Real Incomes of the Poor" in National Journal. Disponível em http://www.socialanalysis.org/, Letters to the Editor in Debates.

REDDY, S. \& MINOIU, C. (2007). "Has World Poverty Really Fallen”. Institute of Social Analysis. URL: http: //ssrn.com/abstract $=921153$.

ROSDOLSKY, R. (1977). The Making of Marx's Capital. Pluto Press, London.

SKLAIR, L. (2001). The Transnatinal Capitalist Class , Blackwell Publishers, Oxford.

STERNBERG, F. (1955). Marx und die Gegenwart. Entwicklungstendenzen in der zweiten Hälfte des 20. Jahrhunderts, Verlag für Politik und Wirtschaft, Köln.

STRACHEY, J. (1956). Contemporary Capitalism. Pickering \& Chatto Ltd, London.

UNDP (2007). URL: http://www.umverteilung.de/entundp.htm. 